\title{
El proyecto migratorio de los indocumentados según género
}

\author{
Antonio Izquierdo Escribano \\ Universidade da Coruña. Departamento de Socioloxía \\ Campus de Elviña. 15071 A Coruña \\ anizes@udc.es
}

\section{Resumen}

Este artículo se centra en las motivaciones diferenciales de la inmigración femenina respecto a las de los hombres, entendiendo que éstas están estrechamente relacionadas con las de los varones, especialmente en contextos en que la ley favorece los vínculos familiares. Para su análisis el autor utiliza los datos de una encuesta que levantó el CIS entre mayo y agosto de 1996, incluyendo un 11,5\% de las solicitudes de permisos de trabajo que se presentaron a la regularización en toda España. Bajo esta perspectiva de diversidad de proyectos y condiciones diferenciales de integración en base al género el artículo persigue tres objetivos básicos: 1) dar contenido al proyecto migratorio teniendo en cuenta la totalidad del ciclo; 2) romper con la imagen estereotipada que se tiene del indocumentado - que se trata de una persona analfabeta - y mostrar además el perfil real de éste y 3) analizar el componente heterogéneo de las migraciones desde los cruces de las variables de sexo y nacionalidad en base a las motivaciones a la emigración, contextualizadas en las diferentes etapas de las políticas de inmigración española (pre-legal, pre-política y política).

Palabras clave: heterogeneidad, indocumentados, motivaciones diferenciales a la emigración (género, nacionalidad, temporalidad), proyecto migratorio, recursos educativos, regularización de 1996.

\section{Abstract. The migratory project of undocumented migrants by gender}

This article is based on the different character of the migratory project according to gender. However, different female motives are also interlinked with those of men, as a result of the migratory dynamics, which foster family migration. With this aim, the author uses survey data which includes a 11,5 per cent of the work permits application of the 1996 regularisation of foreigners in Spain. Throught the diversity of projects and conditions for social integration according to gender, the article sustains three basic ideas: 1) the acknowledgement of the whole of the migratory cicle; 2) a need to go beyond the stereotyped image of the indocumented migrant, especially seen as illiterate, and 3) to analyse the heterogeneous component of migration flows particularly when cross-cutting the following variables: sex and nationality, contextualised in the different periods of the Spanish immigration policies (pre-legal, pre-political and political).

Key words: heteorgeneity, undocumented, differentiated motivations to emigration (gender, nationality, temporality), migratory project, educational resources, 1996 regularisation. 


\section{Sumario}
1. El plan migratorio
7. La razón más importante
2. La intención y el método
8. Las razones para emigrar
3. Los poros de la encuesta según la nacionalidad
4. Unos protagonistas bien educados
9. La mirada en el tiempo
5. El viaje a alguna parte
10. Conclusión
6. Las razones invocadas para venir
Bibliografía

a España

Este artículo persigue tres empeños. Empieza con la propuesta de dar contenido al denominado "proyecto migratorio». No suele definirse y menos aún calcular su alcance en lo que atañe a la instalación y a la convivencia. En mi opinión el proyecto migratorio es una disposición de ánimo que cubre todo el periplo, no más y tampoco menos. Se trata de un tejido fibroso hecho de actitudes, expectativas e imágenes que se traen y que se llevan los migrantes. El proyecto puede estar cargado de ensoñación o contener una alta dosis de información veraz sobre el punto de llegada. En todo caso, los golpes de realidad que recibe aquí y allá moldean y repintan el mencionado plan. La influencia que tiene el tal proyecto en cada paso de la integración y de la exclusión de los inmigrantes es harina de otro costal.

El segundo objetivo que aquí se intenta es el de romper con la imagen del indocumentado que no sabe leer. La emigración es selectiva y no se va del país el hombre o la mujer promedio. Los promedios no emigran al igual que los indicadores no aseguran comportamientos. Ni siquiera estoy convencido de que los auguren. No emigran (necesariamente) las familias más numerosas, ni los hombres que practican la poligamia, ni tampoco las mujeres reducen el número de hijos porque la relación entre la población y los recursos ande desequilibrada. No es así. La tasa de paro y la de crecimiento medio anual de la población no predicen una migración masiva y menos aún un destino concreto. No emigran, en todo tiempo y lugar, los más pobres ni los desempleados. Ese perfil no lo cumplen la mayoría de los que vienen a España. La inmigración que recibimos sabe leer y tiene títulos. Tenía trabajo en el país de origen y no estaba ubicada en el grupo de las personas más prolíficas ${ }^{1}$.

El tercer argumento es el de la comparación de lo heterogéneo. Podríamos buscar razones ocultas para la emigración e intereses no confesados, pero nos fiamos de los entrevistados y del instrumento. Damos voz y credibilidad a los motivos que aducen los protagonistas del movimiento. Aunque, para no quedarnos en la piel del asunto, romperemos en dos pedazos el conjunto de los extranjeros separando a los hombres de las mujeres. Al contraste según el sexo

1. Las nuevas migraciones movilizan mayoritariamente a personas provenientes del Tercer Mundo, empujadas por la pobreza o por la violencia política de sus países de origen (Juliano, 1994). 
se añade el desglose que atiende a la nacionalidad. Así, la muestra, resulta troceada en aras de un legítimo ejercicio de análisis sociológico. Eso sí, advertimos al lector de las debilidades que tiene nuestro juego, en un apartado dedicado a los poros de la encuesta.

Y ya está resumido el orden y la sustancia del artículo. Un proyecto, una herramienta, unos protagonistas y sus razones. El método y la intención aparecen por doquier y, también, de un modo explícito.

\section{El plan migratorio}

$\mathrm{El}$ «proyecto migratorio» tiene, según lo veo, tres puntos de apoyo ${ }^{2}$. El primero es el motivo aducido para emigrar hacia un destino concreto. El segundo son los planes de establecerse. Y el tercero lo constituyen las expectativas (cuando las hay) de retorno. Son planes que se guardan en la maleta de la mente. El proyecto prefigura el entero ciclo migratorio. Lo abre y lo cierra. Supone una secuencia de movimientos, cada uno de ellos con plazos fijos y variables. En el núcleo lleva un programa con su calendario. Ese horizonte temporal influye, sin duda, en las pautas de consumo y acomodación al entorno. Pero también en la falta de aclimatación y de integración al mismo. Así, cuando los migrantes compran una vivienda es fácil concluir que están pensando en establecerse. Si se trae o se forma una familia se busca otro tanto de lo mismo. Claro que la voluntad tropieza con obstáculos de todo orden que, en ocasiones, resultan insalvables. Pero no es de esto de lo que aquí se va a hablar. Únicamente sostengo que el proyecto migratorio no se consume en el movimiento de salida. La emigración no es el proyecto, es el principio. El proyecto está presente a lo largo del recorrido, desde la salida hasta la instalación y, en su caso, incluye un eventual retorno.

Atendamos a lo que es previo. En un principio el proyecto se levanta sobre la frustración (y en ocasiones la carencia) de expectativas laborales, dinerarias y de libertad para organizar la vida individual y social. Esas privaciones relativas se notan donde se nace. Aunque éstos no sean los únicos motivos para marcharse de un país, son los que más pesan en la hora actual. El sentido común dice que esas razones cambian a la par que lo hacen las condiciones sociales en el origen y varían con las circunstancias y características de los migrantes.

El segundo pilar del proyecto se lleva en la memoria pero cuaja en el destino. Se va forjando en el choque de la imagen que se tiene del paradero y las condiciones reales de vida que los inmigrantes experimentan allí donde llegan. La cuestión es por qué unos deciden quedarse y otros no, y cuándo y en qué situación toman la decisión. Sabemos, eso sí, que hay inmigrantes que optan por una estancia temporal, otros que se han fijado un período de prueba $y$,

2. El Colectivo IOÉ reduce el proyecto migratorio (en plural) a los motivos para emigrar y así se pregunta ¿Cuál es la motivación que impulsa a estas personas a dejar sus países para venir a España? (Colectivo IOÉ, 1998). 
por último, están los que se muestran firmes en el propósito de establecerse aquí, en España, de por vida. En pocas palabras, el proyecto de las gentes que se mueven, se nutre de los motivos para irse de un lugar y de las razones para quedarse en otro. Tal y como aquí se define el proyecto migratorio, constituye el telón de fondo para interpretar los procesos concretos de integración. Lo que cabe averiguar es cómo y en qué influye el proyecto que traen los inmigrantes respecto de su acomodo laboral, su acceso a la vivienda y su conducta familiar por tomar tres anclajes de la instalación permanente.

La tercera columna del proyecto nos completa el ciclo migratorio. Pues de eso se trata. Cuando las gentes emigran llevan preparado el recorrido. Se quiere de ida y vuelta. El regreso se presagia exitoso o tranquilo. Una proporción significativa así lo reconoce. Luego los planes se tuercen, las estancias se prolongan y hasta los retornos, cuando se producen, fallan en sus conjeturas. Ocurre que el lugar de origen, más aún cuando se tarda mucho en visitarlo, aparece extraño y hostil. Incluso las vueltas asiduas de aquéllos que pueden hacerlo, desembocan, con no poca frecuencia, en una instalación definitiva en el país de adopción. La estabilidad jurídica y familiar alcanzada en el destino o la situación laboral que se vive en el terruño zanjan de un modo definitivo la cuestión del retorno.

El fundamento primero sobre el que se sostiene el plan del inmigrante es el que se va a explorar en este artículo. Vamos a escudriñar por qué se marchan de su tierra. La indagación se fundamenta en las razones invocadas por los protagonistas para emigrar con destino a España. El segundo eje del proyecto, a saber, la intención de permanecer poco o mucho tiempo en el país, queda fuera de estas páginas. El tercer y último pivote de plan es de imposible dibujo con esta encuesta. No hay preguntas que lo aborden.

\section{La intención y el método}

En el título del artículo asoman las intenciones. Hoy en día en la universidad anda todo el mundo, es un decir, hurgando en las diferencias. Estoy convencido de que en este número monográfico de PAPERS los lectores encontrarán abundantes pruebas de ello. Pues bien, nosotros vamos a desplegar una comparación entre mujeres y hombres respecto de los motivos para emigrar ${ }^{3}$. Lo adecuado es señalar tanto las coincidencias como los desacuerdos. Conscientes de la influencia que tiene la diversidad, ahondaremos en las diferencias que se dan entre las propias mujeres inmigrantes según la nacionalidad. Si se me permite la redundancia, buscamos lo heterogéneo dentro de la diferencia. Este método de comparar ambos sexos y después desagregar por nacionalidad sigue una lógica que persigue, dicho con toda claridad, subrayar las diferencias y profundizar en la distinción.

3. La migración de mujeres está relacionada estrechamente con la de los hombres, particularmente en el contexto en que la ley o las regulaciones en materias de migración favorecen la selección de inmigrantes basándose en los vínculos familiares (Zlotnik, 1998). 
Sin embargo, en la interpretación de los motivos para emigrar de los hombres y mujeres se pueden seguir otros caminos. Sendas que acentúan las convergencias y atemperan los contrastes. Dimensiones del análisis que añaden un gramo de contexto a la lógica de las identidades. Tal sucede cuando se observan las razones para emigrar según el año en el que llegaron. Por expresarlo de un modo más riguroso, la perspectiva temporal gradúa los motivos y los contextos armonizan aunque no igualan. En definitiva, hay métodos que resaltan las singularidades y otros en los que las coincidencias se perciben con mayor intensidad. No lo olvide el lector, y si tiene paciencia, al final del recorrido tendrá una pista de lo que aquí se anuncia.

\section{Los poros de la encuesta}

Los datos que se van a manejar en este artículo proceden de una encuesta que levantó el Centro de Investigaciones Sociológicas (CIS) entre mayo y agosto de 1996. Se seleccionaron nueve provincias (Madrid, Barcelona, Málaga, Las Palmas, Valencia, Alicante, Almería, Murcia y Gerona) para realizar 1.981 entrevistas. La muestra representa el 11,5\% de las solicitudes de permisos de trabajo que se presentaron a la regularización en toda España. Según el Ministerio del Interior fueron 17.225 los permisos de trabajo y residencia solicitados, mientras que el Ministerio de Trabajo y Asuntos Sociales (MTAS) ofrece el dato de 17.676. En las nueve provincias donde se realizaron las entrevistas se presentaron 14.433 solicitudes, es decir, el $81 \%$ del total, dando por buenos los datos del MTAS, que fue el que encargó al CIS esta encuesta.

En un apartado dedicado a la herramienta hay que poner en claro sus limitaciones para que luego, a lo largo del texto, el lector no se llame a engaño. Pues bien, a esta encuesta se le pueden poner dos reparos que incumben a los fundamentos del artículo: el reparto por nacionalidad y sexo. Desde luego, hay otras cortapisas pero éstas son las que dejan una huella más marcada en la fiabilidad de las medidas, aunque no tanto en la validez de los resultados. Claro está que la interpretación y los argumentos que aquí se construyen tienen una naturaleza distinta.

Un modo de comprobar la consistencia de la muestra es enfrentarla con estadísticas de otra factura. En la encuesta se entrevistaron a 588 mujeres y a 1.393 hombres y, según las preguntas, siempre existen casos perdidos. Por eso en la base de las tablas figura el número de casos válidos. Cuando se contrasta esta distribución según el sexo con otros registros administrativos y fuentes estadísticas se aprecia una ligera subrepresentación de las extranjeras en la pesquisa del CIS (tabla 1).

Más concretamente, el peso de las inmigrantes indocumentadas que aparecen en la encuesta es cuatro puntos porcentuales inferior al de las trabajadoras extranjeras con el permiso en vigor. Además, las irregulares captadas en las colas de las delegaciones provinciales de trabajo subestiman en un $2 \%$ el porcentaje de extranjeras que pidieron un permiso de trabajo en la regularización de 1996. Estas pequeñas diferencias no enturbian los resultados del conjun- 
to, pero sí que afectan al análisis por nacionalidades habida cuenta de la escasa representación que alcanzan algunas de ellas. Así pues, lo que se diga sobre el particular debe ser tomado como un indicio y no como una prueba.

El detalle por nacionalidad añade riesgo al ejercicio anterior. Vean, en forma comparada, la distribución de mujeres según las varias fuentes estadísticas (tabla 2). Sobran los comentarios. Ahí se ve lo cerca que está la encuesta de la población femenina regularizada y lo desviada que anda la muestra respecto del stock de trabajadoras dominicanas en situación legal, por tomar el caso más significativo.

Con todo y ser eso cierto, la aproximación que aquí se hace es la más reciente y válida respecto de la inmigración que se encuentra en situación irregular. El lector tiene ya los datos básicos y ahora puede acompañarme por el recorrido con más garantías y menos vendas en los ojos. Pongámonos a ello. Empecemos por colorear el perfil de los protagonistas.

Tabla 1. Distribución por sexo de los extranjeros que solicitaron la regularización y del stock al 31-12-1995.

\begin{tabular}{lcll}
\hline & Núm. casos & Varón & Mujer \\
\hline Encuesta CIS & 1.981 & 70,3 & 29,7 \\
DGOM $^{1}$ & 14.653 & 68,3 & 31,7 \\
MTAS $^{2}$ & 13.511 & 68,0 & 32,0 \\
Stock $1995^{3}$ & 139.038 & 66,8 & 33,2 \\
\hline
\end{tabular}

1. Se trata de resoluciones favorables al 16-XII-97. Datos de la Dirección General de Ordenación de las Migraciones.

2. Permisos de trabajo resueltos (incluye los denegados). Explotación pedida por el autor. Subdirección General de Estadísticas Sociales y Laborales, MTAS.

3. Permisos de trabajo en vigor al 31-XII-1995. Estadística de Permisos de Trabajo a Extranjeros, 1996.

Tabla 2. Extranjeras según nacionalidad en diversas fuentes estadísticas.

\begin{tabular}{lcrrrrr}
\hline & CIS-96 & \multicolumn{1}{c}{$\%$} & MTAS $^{1}$ & \multicolumn{1}{c}{$\%$} & \multicolumn{1}{c}{ Stock 95 } & \multicolumn{1}{c}{$\%$} \\
\hline Marruecos & 94 & 16,0 & 758 & 17,7 & 7.850 & 17,0 \\
Perú & 79 & 13,4 & 500 & 11,7 & 7.287 & 15,8 \\
R. Dominicana & 49 & 8,3 & 387 & 9,0 & 8.384 & 18,2 \\
Argentina & 43 & 7,3 & 264 & 6,2 & 2.592 & 5,6 \\
China & 37 & 6,3 & 306 & 7,2 & 1.749 & 3,8 \\
Polonia & 37 & 6,3 & 289 & 6,8 & 638 & 1,4 \\
\hline Subtotal & 339 & 57,7 & 2.504 & 58,6 & 28.500 & 61,8 \\
\hline Resto & 249 & 42,3 & 1.769 & 41,4 & 17.633 & 38,2 \\
\hline Total & 588 & $(100)$ & 4.273 & $(100)$ & 46.133 & $(100)$ \\
\hline
\end{tabular}

1. Permisos de trabajo concedidos a mujeres solicitantes de la regularización. 


\section{Unos protagonistas bien educados}

La mayoría de nuestros dos mil entrevistados se hallan en plena edad productiva. Dicho con mayor precisión, ocho de cada diez hombres están entre los 25 y los 44 años de edad, y en el mismo intervalo se encuentran dos de cada tres mujeres. Un tercio de las mujeres se reparte entre las jóvenes y las maduras: exactamente el $18 \%$ de las indocumentadas no había cumplido los veinticinco años y el $15 \%$ rebasaba los cuarenta y cinco. De aquí se deduce que en ambos sexos domina la silueta de los trabajadores, aunque también se apunta la reunión familiar que está muy presente entre las mujeres de más edad.

La distribución según el estado civil consolida estas presunciones. En los hombres sobresale la soltería (45\%), mientras que entre las mujeres destacan las casadas $(46 \%)$. La proporción de mujeres que vive en pareja (12\%) o que está separada o divorciada (10\%) es siempre superior al porcentaje de hombres que se encuentran en esas situaciones (9 y $4 \%$ respectivamente). Sólo tres de cada diez mujeres «sin papeles» se declara soltera.

En la procedencia o más precisamente en la nacionalidad es donde las diferencias entre hombres y mujeres resultan más vivas. La mitad de los indocumentados viene de Marruecos (42\%) y de Argelia (8\%) frente a sólo el 16\% de las mujeres indocumentadas. La inmigración norteafricana tiene, todavía, un índice de masculinidad muy alto. En cambio, la proporción de mujeres latinoamericanas, asiáticas y europeas supera ampliamente el peso de los hombres. Estas migraciones están feminizadas.

Por último, en este esbozo comparado de los indocumentados según género, nos fijaremos en los recursos educativos. Lo primero que conviene destacar es que los inmigrantes andan bien pertrechados en lo que a estudios se refiere. Desde luego se hallan claramente por encima de la media en sus respectivos países. En éste y en otros aspectos la inmigración resulta selecta (aunque el hecho de que los cuestionarios y los entrevistadores sólo se expresaran en español probablemente sobreeestima los títulos y diplomas del conjunto). Pues bien, la riqueza educativa de las mujeres es aún mayor. Un $17 \%$ posee título universitario y otro $41 \%$ ha completado los estudios de grado medio. Apenas un $18 \%$ no ha terminado los estudios primarios. En cambio, un tercio de los hombres no tiene los estudios más elementales, el $25 \%$ ha finalizado la educación primaria y el resto tiene un título medio (31\%) o superior (12\%). Así pues, las mujeres inmigrantes superan a los hombres en lo que a recursos educativos se refiere. Todo esto se predica de los indocumentados en 1996 y con las cautelas debidas a las limitaciones de la encuesta que se han señalado con anterioridad ${ }^{4}$.

No obstante lo cual, en el interior de la inmigración femenina las diferencias son importantes. Tomemos los seis países con un mayor número de muje-

4. El resultado es otro según Carrasco Carpio: «El nivel de estudios alcanzados por el varón es ligeramente superior al de la mujer». Y, sin embargo, en su encuesta también es mayor la proporción de mujeres que han terminado los estudios universitarios y secundarios (Carrasco, 1999: 107-108). 
Tabla 3. Mujeres indocumentadas según nacionalidad y estudios terminados.

\begin{tabular}{|c|c|c|c|c|c|c|c|}
\hline & Analfabetos & $\begin{array}{l}\text { Leer } \\
\text { y escribir }\end{array}$ & $\begin{array}{l}\text { Antes } \\
\text { primarios }\end{array}$ & Primarios & Secundarios & Universitarios & $\begin{array}{l}\text { Núm. } \\
\text { casos }\end{array}$ \\
\hline Argentina & & 2,3 & & 30,2 & 44,2 & 23,3 & 43 \\
\hline Perú & & 2,5 & 5,1 & 21,5 & 53,2 & 17,7 & 79 \\
\hline R. Dominicana & & 4,2 & 18,8 & 39,6 & 29,2 & 8,3 & 49 \\
\hline China & & 10,8 & 8,1 & 37,8 & 40,5 & 2,7 & 37 \\
\hline Polonia & & & 2,9 & 65,7 & & 31,4 & 37 \\
\hline Marruecos & 11,8 & 15,1 & 18,3 & 28,0 & 22,6 & 4,3 & 94 \\
\hline Total & 3,3 & 6,9 & 9,9 & 26,9 & 40,0 & 13,1 & 339 \\
\hline
\end{tabular}

Fuente: CIS, Estudio no 2.216, 1996.

res. Se trata de tres países latinoamericanos (Argentina, Perú y República Dominicana) junto a China, Polonia y Marruecos (tabla 3).

Las inmigrantes marroquíes sobresalen entre los analfabetos (12\%), a lo que cabe añadir un 33\% que no ha completado la educación primaria. Sólo una de cada cuatro mujeres que provienen de Marruecos ha superado con éxito los estudios de grado medio. En el otro extremo de la educación reglada se encuentran las inmigrantes polacas. Vienen, por así decirlo, sobradas de títulos educativos: una de cada tres es licenciada universitaria y el resto $(66 \%)$ son mujeres que han terminado los estudios de grado medio. También en la parte alta de la pirámide educativa encontramos a las inmigrantes argentinas y peruanas. Entre ellas apenas se cuentan personas que no tengan completa, como mínimo, la educación general básica. La mitad de estas mujeres han cursado la secundaria $y$ alrededor de un $20 \%$ son tituladas superiores.

En la franja intermedia se hallan las inmigrantes chinas repartidas en los siguientes tres tramos educativos: $41 \%$ terminó la secundaria, $38 \%$ la primaria y un 19\% que apenas sabe leer y escribir. Por fin, en los escalones más bajos de la educación formal (pero por encima de las mujeres marroquíes) se sitúan las dominicanas, una de cada cuatro no acabó la primaria, el $40 \%$ sí lo hizo y el resto tiene estudios medios e incluso un $8 \%$ posee un título universitario. Así pues, polacas, argentinas y peruanas se situan en la parte alta de la escala educativa. En la mitad se encuentran las inmigrantes chinas y después las mujeres dominicanas. Por fin, y abajo del todo, las indocumentadas marroquíes.

\section{El viaje a alguna parte}

No estamos en un país de tránsito para los inmigrantes extranjeros, aunque una porción minoritaria lo usa como puente hacia otros lugares. Así, nueve de cada diez inmigrantes «sin papeles» responden que España era el país europeo que habían elegido inicialmente como destino. Por detrás de España aparecen Francia y Alemania. 
De modo que los inmigrantes vienen, por así decirlo, a tiro fijo. Ése es el dato y el hecho. No todos, pero sí la mayoría. Es probable que en el caso de nuestra encuesta la proporción resulte algo exagerada por tratarse de «inmigrantes resistentes». Es decir, de extranjeros que cumplían las condiciones exigidas para conseguir la regularización, a saber: haber sido titulares de un permiso con posterioridad al 26 de mayo de 1986 o ser familiar de un extranjero que reside legalmente o que vive en una situación de «irregularidad sobrevenida».

Así pues, una preferencia por España tan abrumadora se explica, en parte, por la antigüedad de los entrevistados. Otros estudios levantados entre inmigrantes menos bregados arroja proporciones acordes con su menor arraigo. Pero todos coinciden en que es una mayoría la que responde que su meta es España. Convendría, sin embargo, medir la proporción de aquéllos que desde el principio han optado por España. Es útil separarlos de los que adoptan esa decisión con el paso del tiempo y forzados por las circunstancias. Sospecho que habrá algunas diferencias. Aún más, resulta recomendable que año tras año se haga esta pregunta en el instante en el que los extranjeros entran por primera vez en el país para ver su evolución.

Apenas si existen diferencias entre hombres y mujeres a la hora de señalar el paradero. Las mujeres rebasan en cuatro puntos porcentuales a los hombres. La ventaja es estrecha para darle un significado especial. El margen bien puede deberse al error del procedimiento. Así pues, no cabe, por el momento, buscarle tres pies al gato y lo más sensato es concluir que respecto a la selección del destino no se aprecian discrepancias según género (tabla 4).

Si nos detenemos en las seis nacionalidades más relevantes, el contraste no consigue entonarse (tabla 5).

Tabla 4. España como país elegido según sexo.

\begin{tabular}{lcc}
\hline & Hombres (\%) & Mujeres (\%) \\
\hline Sí era el país elegido & 89 & 93 \\
No era el país elegido & 11 & 7 \\
Núm. de casos & $(1.393)$ & $(588)$ \\
\hline
\end{tabular}

Tabla 5. España país elegido según nacionalidad en \%.

\begin{tabular}{lcc}
\hline & Hombres & Mujeres \\
\hline R. Dominicana & 95,8 & 89,8 \\
Argentina & 89,2 & 93,0 \\
Perú & 87,7 & 89,9 \\
Polonia & 86,3 & 89,2 \\
China & 95,7 & 100,0 \\
Marruecos & 92,4 & 94,6 \\
Núm. de casos & $(829)$ & $(338)$ \\
\hline
\end{tabular}

Fuente: CIS, Estudio no 2.216, 1996. 
Se confirma la tendencia según la cual las mujeres eligen a España como destino en una proporción levemente superior a la de los hombres. Esa pequeña diferencia tal vez se deba al tirón del componente familiar en esta regularización. Una porción de ellas vienen, por así decirlo, empujadas o imantadas por la parentela, cualquiera que sea la fuerza del vínculo y quien lo ejerza. La única nota discordante en este panorama por nacionalidad la ponen las mujeres que proceden de la República Dominicana, pero la diferencia no es «nada del otro mundo». Quizás se debe al poder de atracción que ejercen los EEUU pero no cabe olvidar lo raquítico de la muestra 5 .

\section{Las razones invocadas para venir a España}

Si a una persona que le interesa e incluso le ocupa la cuestión de la inmigración se le pide que diga cuales son las razones por las que vienen los extranjeros a España, es seguro que acierta a la primera. Responderá que vienen en busca de trabajo. Pero es también muy probable que esa persona no tenga el mismo tino cuando se trate de escoger el segundo, el tercero y no digamos el cuarto motivo. Y no se trata de una cuestión sin importancia, porque esos motivos secundarios van al alza rebañándole peso a la causa principal.

La multirrespuesta de los dos mil entrevistados arroja un triple empate entre la búsqueda de más libertad, el ansia de ganar dinero y la necesidad de reunirse con los familiares. Obsérvese cuál fue la pregunta y la distribución que resulta al señalar una y como máximo dos razones (tabla 6).

La razón laboral triplica a las tres que le siguen, pero pocos habrían aventurado ese empate tan singular entre familia, democracia y consumo. La búsqueda de trabajo no equivale a que emigren los que están desempleados en el país de origen. El coste económico del viaje y el dinero necesario para evadir los obstáculos que se ponen a la entrada también excluye a los más pobres. Por último, el equipaje de estudios con el que vienen confirma que no son mayoría los desheredados. Exploremos ahora las diferencias que, en este punto, podemos encontrar entre los extranjeros y las extranjeras. Vamos a concentrarnos sólo en la primera razón.

\section{La razón más importante}

Se ha convertido en un lugar común que los motivos para emigrar de las mujeres y de los hombres son diferentes. Sin embargo, no resultan tan evidentes los matices y la magnitud de esas discrepancias ${ }^{6}$. Se dice que en los hombres es

5. En el caso de la República Dominicana, la respuesta parece estribar en los vínculos con los EEUU creados con la invasión de Santo Domingo en 1965 por los marines estadounidenses (Sassen, 1994).

6. Puesto que evidentemente contamos con poca documentación sobre la dinámica de la migración femenina, continúa siendo limitada la posibilidad de lograr mayor penetración en las causas y las consecuencias de esta migración (Zlotnik, 1998). 
Tabla 6. ¿Cuál fue la razón o las dos razones más importantes que, en su caso concreto, le han hecho decidir venir a España?

Multirrespuesta: máximo dos respuestas $\quad \%$

Tener más libertad $\quad 21,7$

Buscar trabajo $\quad 60,7$

Tener estudios, formación $\quad 9,8$

Ganar más dinero $\quad 21,6$

Reunirse con familiares 22,1

$\begin{array}{ll}\text { Otra razón } & 6,7\end{array}$

No de casos válidos (1.970)

Fuente: CIS, Estudio no 2.216, 1996.

Tabla 7. Primera razón para emigrar.

\begin{tabular}{lcc}
\hline & Hombres & Mujeres \\
\hline Tener más libertad & 24,2 & 14,0 \\
Buscar trabajo & 52,6 & 45,3 \\
Tener estudios & 5,2 & 8,3 \\
Ganar más dinero & 5,4 & 4,0 \\
Reunirse con familiares & 7,2 & 23,5 \\
Otra razón & 5,3 & 4,8 \\
No de casos válidos & $(1.366)$ & $(578)$ \\
\hline
\end{tabular}

Fuente: CIS, Estudio no 2.216, 1996.

el trabajo y que en las mujeres puede más la familia. Eso es decir poco y además equivocarse. La búsqueda de trabajo es el móvil principal sin grandes distingos entre unas y otros. Esta razón duplica a cualquier otra, tanto en los hombres como en las mujeres. Sabemos que los inmigrantes vinieron sobre todo para trabajar, pero también hemos dicho que les animan otros motivos. Es aquí, en esos otros motivos para venir a España, donde las diferencias según el género brillan con más fuerza.

Comparemos la distribución de hombres y mujeres respecto de la razón más importante para venir a España (tabla 7).

En efecto, la razón de más peso es el trabajo. La invocan uno de cada dos hombres y una proporción ligeramente inferior de mujeres (45\%). Sin embargo, por detrás de esta coincidencia asoman dos mundos distintos. Un hombre de cada cuatro aduce una razón "política» como primer motivo para venir a España, a saber: tener más libertad. En el caso de las mujeres una proporción similar alega que el motivo principal para venir a España ha sido reunirse con los familiares. Se trata de un fundamento más social que el anterior, 
aunque quizá este argumento resulte agrandado por los requisitos que impuso la regularización de $1996^{7}$.

El resto de las razones para emigrar hacia España tienen menor entidad. Me permito, sin embargo, subrayar que las mujeres extranjeras, en una proporción algo superior a los hombres, vienen para estudiar y formarse. Además sabemos que su bagaje educativo es mayor, lo que da solidez y profundidad a su respuesta. No importa tanto que tengan más estudios cuanto que esa aspiración es más fuerte en ellas. Sugiere una integración menos apresurada, menos avariciosa, con más juicio y sentido de la realidad. Aspiran a tener independencia y más posibilidades de decidir (el «apoderamiento» que ahora se dice). Por último, quizá hombres y mujeres inmigrantes se refieran a cosas distintas cuando señalan la necesidad de «tener más libertad».

Sin embargo, el peso cuantitativo y simbólico que adquiere la emigración en busca de más libertad no guarda relación con el escaso volumen de solicitantes de asilo y refugio en España. Probablemente el contraste sólo se dé en apariencia y la respuesta más sencilla sea que en este caso no se trata de perseguidos.

No son activistas ni represaliados políticos, sino necesitados de libertad. No huyen de la persecución política, religiosa o étnica, sino más bien de la violencia en las calles y en los hogares. Emigran por la inseguridad y el miedo que genera la injusticia y la desigualdad social. Les asusta la inequidad creciente. No son pobres, ni mancos de espíritu, sino, en todo caso, buscadores de respeto.

\section{Las razones para emigrar según la nacionalidad}

Si bien el primer motivo de las mujeres para emigrar hacia España es el laboral y el segundo el familiar, eso no es válido, en igual medida, para todas las nacionalidades. Volvamos de nuevo a los seis países más relevantes con el fin de apreciar las diferencias (tabla 8).

Dentro de la inmigración latinoamericana, las diferencias de grado son importantes. Para las dominicanas el reagrupamiento familiar apenas cuenta como motivo principal. Su razón, casi en régimen de monopolio, es el trabajo y el dinero. En cambio, para las mujeres argentinas y sobre todo para las peruanas la familia es una razón de peso. El ansia de libertad y de ganar más dinero cuenta más para las argentinas, mientras que acumular estudios y formarse profesionalmente es un motivo en el que las inmigrantes peruanas destacan por encima de la media.

El deseo de más libertad va unido a la calidad de los recursos educativos que se atesoran. No cabe extrañarse de que las mujeres polacas resalten en comparación con las demás. Pero también sobresale en ellas el motivo de la reunión con la familia. Eso se explica porque tres de cada cuatro mujeres polacas

7. Las mejores perspectivas de trabajo y acompañar un familiar son las razones principales invocadas en la decisión de emigrar (Bidegain y Pellegrino, 1986). 
Tabla 8. Razón principal de las mujeres por nacionalidad (\%).

\begin{tabular}{lcccccc}
\hline & $\mathbf{1}$ & $\mathbf{2}$ & $\mathbf{3}$ & \multicolumn{1}{c}{$\mathbf{4}$} & \multicolumn{1}{c}{$\mathbf{5}$} & $\mathbf{6}$ \\
\hline Argentina & 14,3 & 38,1 & 4,8 & 11,9 & 23,8 & 7,1 \\
Perú & 6,4 & 44,9 & 9,0 & 6,4 & 28,2 & 5,1 \\
R. Dominicana & 4,1 & 75,5 & 4,1 & 10,2 & 4,1 & 4,1 \\
R.P. China & 5,4 & 70,3 & 2,7 & & 21,6 & - \\
Polonia & 16,2 & 43,2 & - & 8,1 & 29,7 & 2,7 \\
Marruecos & 10,9 & 59,8 & 3,3 & - & 21,7 & 4,3 \\
\hline Total & $(9,3)$ & $(54,9)$ & $(4,5)$ & $(5,4)$ & $(21,8)$ & $(4,2)$ \\
\hline
\end{tabular}

1. Tener más libertad; 2. Buscar trabajo; 3. Estudios y formación; 4. Ganar más dinero; 5. Reunirse con la familia; 6. Otra razón.

Fuente: CIS, Estudio no 2.216, 1996.

están casadas y las demás viven en pareja. Apenas un 3\% se declaran solteras. En las inmigrantes chinas domina intensamente el motivo laboral y eso les sucede también a las marroquíes, que son las que andaban más huérfanas de estudios.

En resumen, las mujeres chinas y marroquíes son las económicamente más necesitadas. Argentinas y polacas son las que se encuentran en una situación más acomodada. Estudios, ingresos y vivienda hacen su vida más placentera. Peruanas y dominicanas aparecen más cargadas de hijos y a la vez son las que los tienen más lejos. Su proyecto migratorio nada aún entre las dos orillas. Pero de esto, de sus planes de quedarse, se hablará en otro lugar. Veamos ahora si el tiempo es capaz de borrar las diferencias en las razones para emigrar.

\section{La mirada en el tiempo}

Bien, ya sabemos que las razones que empujan a la emigración a los hombres y a las mujeres tienen un denominador común y algún acento distinto. También hemos visto como el tono se hace más agudo cuando los motivos de las mujeres se empapan en el país de origen o más rigurosamente se injertan en la nacionalidad; lástima que no se tenga en cuenta en la encuesta la distinción étnica. Pues bien, un corte en el tiempo nos proporciona otra perspectiva. Aparece otro ángulo del asunto, otro enfoque, otra mirada. Veamos ahora los motivos para emigrar según el año de llegada a España.

La política de inmigración que se ha seguido en España desde 1985 ha moldeado los flujos y la población inmigrante que permanece. De modo que hemos aplicado ese criterio a la hora de abrir y cerrar los períodos. El primer corte en el tiempo es, por así decirlo, el «prelegal». Aunque la Ley de asilo y refugio es de 1984, apenas cuenta en la configuración de la inmigración, pues el caudal de solicitantes de refugio siempre ha sido escaso. Así pues, antes de 1985 la inmigración discurría sin una específica atadura legal. El segundo inter- 
Tabla 9. Mujeres y motivos para emigrar según la fecha de llegada (\%).

\begin{tabular}{lccrccc}
\hline & $\mathbf{1}$ & $\mathbf{2}$ & $\mathbf{3}$ & $\mathbf{4}$ & $\mathbf{5}$ & $\mathbf{6}$ \\
\hline Prelegal & 16,9 & 28,1 & 18,0 & 5,6 & 24,7 & 6,7 \\
Prepolítica & 14,3 & 55,5 & 6,9 & 2,4 & 16,3 & 4,5 \\
Política & 12,7 & 41,4 & 6,1 & 4,9 & 30,3 & 4,5 \\
\hline Total & 14,0 & 45,3 & 8,3 & 4,0 & 23,5 & 4,8 \\
\hline
\end{tabular}

Fuente: CIS, Estudio no 2.216, 1996.

valo temporal es el prepolítico, es decir, el que transcurre entre la entrada en vigor de la Ley y la Proposición no de Ley de 1991, que lleva aparejada la que hasta la fecha es la más amplia de las regularizaciones. Durante este plazo de tiempo se perfilan las líneas básicas de una política de extranjería. La tercera fase se abre después de la gran regularización y llega hasta la tercera operación para legalizar a los extranjeros en situación irregular en abril de 1996. Aún está abierta y merece calificarse de política ${ }^{8}$. Nos encontramos, pues, con tres etapas y tres fases: la prelegal, la prepolítica y la propiamente política, a saber, la que pone en práctica los contingentes, el Plan para la Integración y la modificación en 1996 del Reglamento de aplicación de la Ley de 1985 con la aportación del permiso permanente (tabla 9).

Aunque en los tres períodos la razón principal es la búsqueda de trabajo, su preponderancia tiene una estatura bien distinta. En la primera época de la inmigración, la previa a la Ley de Extranjería, el argumento laboral (28\%) corre parejo al familiar (25\%). Los estudios y el ansia de libertad como palancas de la emigración no quedan muy lejos de los anteriores (18 y 17\% respectivamente). Se puede concluir que las razones para emigrar estaban muy repartidas.

Luego, en el lustro que separa a la primera de la segunda regularización (1986-91), el motivo más destacado es la búsqueda de trabajo. Esta causa duplica el peso alcanzado en la fase precedente y sobresale de las restantes. Además, los inmigrantes llegan desde todos los rincones y, por lo que se refiere a las nacionalidades más relevantes, sólo se echa en falta a las peruanas.

En el tercer período (1991-1996) la inmigración argentina prácticamente desaparece. También disminuye en cifras relativas el flujo de chinas y marroquíes, mientras se mantiene el vigor de la corriente dominicana y polaca al tiempo que irrumpe la inmigración peruana. En esta tercera fase la razón para emigrar que más crece es el reagrupamiento familiar, atemperándose los demás impulsos.

8. La Ley Orgánica 4/2000 de 11 de enero sobre Derechos y Libertades de los Extranjeros en España y su Integración Social abre, quizás, un nuevo régimen de extranjería. Habrá que esperar para ver cuál es la dirección que se emprende. 
Es el tiempo del tirón de las redes de parientes y de la instalación para la convivencia. Si estamos en lo cierto, entonces se avecina una etapa de investigación empírica sobre la integración social de los inmigrantes establecidos. Hay que pasar de la palabras, programas y proclamas a medir el fracaso y el éxito escolar. Habrá que ofrecer datos sobre la morbilidad de los extranjeros, seguir la evolución de la compra de viviendas, medir la tasa de paro, los matrimonios mixtos, los divorcios, la fecundidad de las foráneas y la tasa de naturalizaciones. En las conferencias y seminarios sobre la inmigración dominará la evaluación de los procesos de integración ${ }^{9}$. Pero de esto trata el segundo pilar del proyecto migratorio, aquél en el que los inmigrantes nos cuentan si tienen decidido quedarse en España y por cuánto tiempo. Otra historia.

\section{Conclusión}

En esta primera cata de los motivos para emigrar hemos comprobado que la elección de España no resulta accidental. Además, los impulsos esgrimidos para marcharse de un país tienen distinta intensidad para hombres y mujeres. Aunque la razón principal para ambos «géneros» sea la búsqueda de trabajo. Las mujeres aducen (con mayor insistencia que los hombres) las ganas de aumentar su formación educativa y, sobre todo, la necesidad de una estabilidad afectiva en pareja y familia. Por el contrario, la libertad y el dinero mueven más a los varones. Sin embargo, tanto o más contraste que el género aporta el desglose por nacionalidad. Cada corriente tiene su particular dinámica demográfica. Las características sociodemográficas de las mujeres migrantes y la procedencia de los flujos iluminan estas variaciones.

Por último, aparece otro modo de ver las cosas. Los diferentes motivos para abandonar un país se gradúan cuando se contemplan según la fecha de llegada. Bajo este prisma, el ansia de libertad pierde fuerza en favor de la conveniencia de la vida en familia. Eso ocurre porque los intervalos temporales no sólo reflejan la situación en el origen y la evolución de la corriente, sino que también modulan su tono según sean las políticas migratorias. Esta es la principal cualidad de tal enfoque. Al cabo, los proyectos se desfiguran pero no acaban de borrarse. Y eso sucede porque el tiempo no lo cura todo.

9. ¿Tienen las mujeres inmigrantes unas condiciones diferenciales de integración en la sociedad receptora? (Malgesini, 1998). 


\section{Bibliografía}

Bidegain, G.; Pellegrino, A. (1986). «La mujer migrante en Venezuela». En La mujer migrante. Venezuela: ILDIS, p. 86-102.

CARRASCO CARPIO, C. (1999). Mercado de trabajo: los inmigrantes económicos. Madrid: Ministerio de Trabajo y Asuntos Sociales.

CIS (1996). Regularización de inmigrantes. Encuesta a extranjeros en situación irregular. Estudio 2.216. Madrid.

COLECTIVO IOÉ (1998). «Mujeres migrantes en España. Proyectos migratorios y trayectorias de género». OFRIM, Consejería de Sanidad y Servicios Sociales de la Comunidad de Madrid, p. 11-39.

Juliano, Dolores (1994). «Pobres mujeres o mujeres pobres». En Extranjeros en el paraíso. Barcelona: Virus, p. 43-52.

MALGESINI, Graciela (1998). «Introducción». En Cruzando Fronteras. Barcelona: Icaria/ FUHEM, p. 11-43.

POTTS, Lydia (1994). «Las inmigrantes en el mercado mundial de mano de obra». En Extranjeros en el paraíso. Barcelona: Virus, p. 75-81.

SASSEN, Saskia (1994). "Why Migration? Tesis contra los modelos de explicación al uso». En Extranjeros en el paraiso. Barcelona: Virus, p. 53-63.

ZlotNiK, Hania (1998). «La migración de mujeres del sur al norte». En Cruzando Fronteras. Barcelona: Icaria/FUHEM, p. 113-147. 